\title{
The informal caregiver's burden of dependent people: Theory and empirical review
}

\author{
Stephanie Carretero*, Jorge Garcés, Francisco Ródenas, Vicente Sanjosé \\ Polibienestar Research Institute, University of Valencia, Avda de los naranjos s/n, 46022 Valencia, Spain
}

\section{A R T I C L E I N F O}

\section{Article history:}

Received 14 January 2008

Received in revised form 10 May 2008

Accepted 15 May 2008

Available online 1 July 2008

\section{Keywords:}

Aging

Long-term care

Policy and psycho-educational programs

\begin{abstract}
A B S T R A C T
This paper reviews the main theories and results of the existing research to date about the concept of the informal caregiver's burden. The explanation of the burden concept, the theoretical approaches which attempt to explain it, the variables which have emerged in the investigation, the predictors of its appearance, as well as the intervention programs developed to relieve burden, allow us to approach the appropriate solutions to deal with the current social and political reality of this problem. In this sense, the psycho-educational intervention programs framed within the respite services jointly with the knowledge of the determining variables of the burden can comprise the first optimal approach in order to effectively deal with the burden problem of the informal caregivers of dependent senior citizens.
\end{abstract}

๑ 2008 Elsevier Ireland Ltd. All rights reserved.

\section{Introduction}

Europe and the USA are currently facing demographic aging with equivalently high rates of senior citizens (AARP, 2006) and consequently, an increase in their dependent population, where dependency is understood as the state in which a person requires the help of others in order to perform daily activities (Council of Europe, 1998). The informal care is the assistance provided by persons from the intimate environment of the dependent person (family, neighbors and friends), who do not possess any training about care and who do not receive any economic retribution for this task. The in-home care provided by informal caregivers, especially by family members, is due to different reasons, the preference of the affected patients to remain in their residence, the high cost of formal resources, and the family-oriented character of Mediterranean society, the most frequent. As a result, the majority of the long-term care burden of dependent people falls upon the informal caregivers.

Thus, there are approximately $5 \%$ of European informal caregivers of dependent people and 15\% of Spanish households which are dedicated to informal care (INE, 2004). The informal caregivers are usually family members, normally females (wife or daughter) between the ages of 45 and 65, without job employment or with part-time employment and a low educational and socioeconomic level (Carretero et al., 2006, 2007). Additionally, the care provision is usually characterized by being supplied in the

\footnotetext{
* Corresponding author. Tel.: +34 963828 184; fax: +34 963828184 .

E-mail address: stephanie.carretero@uv.es (S. Carretero).
}

residence of the dependent person, a house which is often shared, in a continual, intense, and daily way (which can represent over $40 \mathrm{~h}$ a week), and includes diverse types of services which range from personal care and the performance of domestic tasks to emotional support. Generally, this assistance is assumed by a single caregiver; a responsibility which frequently lasts for years, where findings show a weighted average of approximately 5 years for dependent people in different environments (FCA, 2001).

Having outlined this situation, it is not surprising from the social and psychological perspective that there is a major concern regarding the impact of the care situation of a dependent person, which can be generated on the informal caregiver. In this sense, informal care has been conceptualized as a vital stress factor event (Zarit, 2002), which jointly with its chronic character and the lack of foresight about the time of its finalization, has been associated to the negative repercussions on the physical and psychological wellbeing of the informal caregiver. This situation has been generically denominated with the overall term of caregiver burden.

In January 2007, the Law of Promotion of Personal Autonomy and Care to Persons in a Dependency Situation came into force in Spain, thus constituting the fourth column of the welfare state which, for the first time will provide care to this population group with a specific system equivalent to what European countries such as Austria, Luxembourg and Germany have already done previously. Since the institutional implementation of social protection systems in Spain in the early 1980s, the benefits and services for people with disabilities and dependence have been uncoordinated and dispersed between the social security system, the social services, and health care systems. The new law, which will deal with dependent people and their caregivers, however does not 
specifically assume the problems associated with the excessive burden of the persons who informally care for them and it also fails to include intervention alternatives or health and social care coordination methodologies.

As a result, we have performed the following theoretical and empirical revision of the burden concept and the social and psychological intervention programs which will make possible to inform and orient the Spanish Public Administrations and in turn, they will serve as a guide for researchers and professionals involved in the responsibility to handle the problems linked to the burden of the informal caregivers of senior dependent people.

\section{The burden concept: theoretical perspectives about caregiver stress}

At the beginning of the sixtieth decade, Grad and Sainsbury (1963) mentioned this concept for the first time in the scientific bibliography, when they described the burden perceived by family members when caring for their relatives affected by some mental illness in their residence. The definition which was given to the burden concept at that time, and which has been adopted by other authors in a more or less extensive way in the research about the negative repercussions of informal care, has been to assume it as an overall term in order to describe the physical, emotional, and economic consequence of providing care (Gaugler et al., 2000; Mockus Parks and Novielli, 2000).

In this sense, it is worth highlighting the contributions made by Zarit et al. (1980) who identified the burden generated by the provision of care as "a state resulting from the action of taking care of a dependent or elderly person, a state which threatens the physical and mental health of the caregiver", as well as by George and Gwyther (1986) who understood burden as "the persistent difficulty to provide care and the physical, psychological, and emotional problems which caregivers or family members can experience when caring for a relative with a disability or some type of deterioration". Similarly, other authors have described burden as the impact that care has on mental health, physical health, other family relations, the job, and the financial problems of the caregiver (Pearlin et al., 1990; Gaugler et al., 2000).

In spite of the multiple investigations performed in the last three decades, above all in the field of family caregivers of ill patients affected by some dementia such as Alzheimer's disease, the caregiver's burden continues to be an ample term with many definitions; in this respect, there is still no homogeneity in relation to its meaning and use (Friss, 2002).

In an attempt to define the burden in a more specific and detailed way, a differentiation has been made between objective and subjective components, which has given rise to the concepts of subjective and objective burden (Montgomery et al., 1985). In fact, this distinction obeys the specific development of the burden concept and points to the multidimensionality of the impact of care (Montgomery and Borgatta, 1989). Thus, in the first moment, the burden term was elaborated as a subjective perception of the impact of care by the caregiver, where subjective burden refers to the attitudes and emotional reaction of the caregiver faced with the development of the care, such as for example, a low emotional mood, anxiety, or depression. Subsequently, the objective component of the burden was included, which related the objective burden with the dedication to the fulfillment of the caregiver role and involved the specific repercussions on the different areas of the caregiver's life, employment, social life, leisure, etc. (IPA, 2002).

Nonetheless, research has demonstrated that the caregiver burden cannot be summarized in a unique concept, which encompasses multiple dimensions, subject to individual variability and whose process of adaptation fluctuates throughout the care period (Zarit, 2002). They comprise the main reasons why it has been defended that the caregiver burden must be framed within a multi-dimensional process, where different explanatory theoretical models have appeared from psychology regarding the complexity of the caregiver burden.

Basically, from the theoretical viewpoint, the burden has been explained from the psychological perspectives of stress and coping (Gaugler et al., 2000). The majority of theoretical models which have been developed to explain the burden and the stress of the caregiver have been based on the Transactional Stress Theory by Lazarus and Folkman (1984). In this context, the model which has had the greatest influence in the theoretical understanding of the process of the caregiver burden has been the Pearlin Stress Process Model (Pearlin et al., 1989, 1990; Aneshensel et al., 1995; Pearlin and Skaff, 1995). The authors assume a multi-dimensional approach to describe how the care is converted into a burden for some individuals and can lead to physical and psychological reactions in the caregiver.

Specifically, Pearlin and his collaborators defend the influence of the contextual characteristics of the caregiver and the recipient of the care, e.g., sociodemographic variables, in the caregiver's adaptation to the stress process of the care. Furthermore, they propose that there are various types of stress factors, which determine the caregiver burden. Regarding this, they affirm that the care demands (objective primary stress factors) have a repercussion on the caregivers provoking a series of negative emotional reactions (the subjective primary stress factors) in them.

The primary stress factors can, in turn, proliferate in other areas of the caregiver's life (secondary stress factors) and in an objective way, provoke negative repercussions on the free time, social relations, the economic and employment situation of the caregiver (role tensions) and the subjective assessment of these consequences can lead to diminished feelings of self-esteem, expertise, sense of self or competency (intrapsychic tensions). The stress process can be mediated by variables that mitigate the negative impact of the care implications which include strategies of coping and social support, both formal and informal, which alleviate the stress and the negative mental health associated to the care task.

Zarit $(1989,1990)$ has expanded this model, including in a successive way, the secondary assessments, Expanded Theoretical Model of Care, and primary assessments, Modified Stress Process Model of Lazarus and Pearlin (Zarit, 2002), from the theory of Lazarus and Folkman (1984), which, applied to the care context, imply in a respective way, that the caregiver makes a general assessment of his/her own resources in order to confront the threat of the stress factors of the care as well as a subjective evaluation of the objective primary stress factors in terms of threat or challenge.

These theoretical approaches have not ceased to confirm what we have already mentioned above: the multi-dimensionality of the process of the informal caregiver's burden. The revision of the research conducted in this respect equally denotes the multiple variables associated to the caregiver's burden, as well as the different repercussions on the physical and mental well-being of the caregivers.

\section{Empirical results about caregiver stress}

The studies have shown the existence of negative repercussions of the burden on the physical and mental health of the informal caregivers of dependent people. On the one hand, the effects of the caregiver burden on the mental health of the caregivers are essentially depression and anxiety as well as high stress levels; equally it finds that the probability of the development of these disorders is greater in women than in men, and this larger risk is also linked with a greater assumption of responsibility in the 
caregiver task, a greater number of hours providing the care, and a greater physical and cognitive deterioration of the care recipient (Yee and Schulz, 2000). Equally, it is worth noting that the greater incidence of mental health disorders is corroborated by the greater use of psychotropic medicine among the caregivers in comparison with the general population (Noonan and Tennstedt, 1997).

Among the effects on the physical health, although less frequent and intense than the aforementioned effects on the mental health, we find: negative evaluations of their own health, psychosomatic and immunological disorders, cardiovascular problems, and dependency in order to perform the activities of daily life. Similarly, it has found that the caregivers neglect their own health needs, thus they have a lower probability to become involved in preventive health behaviors and to seek medical care These problems generate an increased risk of premature mortality in the caregivers (Lee et al., 2003; Grunfeld et al., 2004).

The caregiver's burden can also lead to major negative consequences for the dependent person, which includes premature institutionalization and mistreatment. The caregiver burden, the emotional discomfort, and indicators of the poor state of health appear as major predictors of the abandonment of the care task and the consequent institutionalization of the dependent person as opposed to the variables of the dependent person- evolution of the disease, behavior problems, cognitive alterations, difficulties in the performance of the daily activities (Logdson et al., 1999).

Nevertheless, according to the Pearlin Stress Process Model, in which the caregiver burden has been conceptualized as a process, the institutionalization does not represent a solution for the care burden: the entry of a dependent person in a center leads to the disappearance of specific stress factors associated with the inhome care period but the appearance of others linked to the institutional care. In addition, the stress developed in the in-home care phase continues to have an influence in the institutional care phase (Pearlin et al., 1989, 1990; Aneshensel et al., 1995; Pearlin and Skaff, 1995).

It has also indicated that the caregivers can be involved in aggressive or violent behaviors towards the care recipient as a consequence of the burden that he/she is experiencing, by means of mistreatment or abuses (Havens, 1999; Mockus Parks and Novielli, 2000).

Several authors have also appealed to the possibility of the existence of positive repercussions of care (Marks et al., 2002; López et al., 2005), where several investigations have indicated an increase of expertise and the feelings of satisfaction derived from caring for a dependent person as the two most relevant positive consequences.

On the other hand, from the empirical viewpoint, multiple investigations have been carried out to identify the variables associated with the caregiver burden, which highlight the following.

Among the variables of the care context, a series of sociodemographic characteristics of the caregiver and the caregivercare recipient relation are associated to the burden levels of the care provider. Specifically, among the sociodemographic variables of the caregiver, a young age, being a female, a low income level of the caregiver and the fact that this person has a job have been associated with very high levels of burden (Navaie-Waliser et al., 2002). Equally, with regards to the relation between the caregiver and the care recipient, the following variables are more intensely related to the caregiver burden: the family relation and whether or not the informal caregiver lives with the patient. Spouses experienced greater levels of excessive burden than the children of dependent people (IPA, 2002), essentially due to the greater physical and emotional closeness of the couples (Gaugler et al., 2000), although it is also necessary to consider in this case, the influence of the gender variable since the daughters and the wives experience similar levels of burden greater than those shown by the sons and the husbands who are caregivers (Hawranik and Strain, 2000). The fact that the caregiver lives with the dependent person is related to high levels of excessive burden, depression, social isolation, and poor state of health, is primarily generated by the greater daily frequency of the care and the greater commitment to maintain the person in the residence (Brodaty and HadziPavlovic, 1990; IPA, 2002).

We note that few studies have been carried out in relation to the sociodemographic variables of the dependent person, essentially given the fact that instead of analysing the influence of the characteristics of the care recipient on the caregiver burden, the majority of the researchers have preferred to focus on the factors associated to the dependence and the disease: the objective primary stress factors. Only a few researchers have indicated in a very general way that a young age and the male gender of the care recipient can be related to a greater caregiver burden (Gaugler et al., 2000).

With regard to the primary stress factors, the influence of behavioral problems generated by dementias or other mental disorders can appear in a severe way, as opposed to the cognitive deficiencies and dependence for the activities of daily life, as generators of excessive burden in the caregiver, emotional discomfort, exhaustion, and emotional mood disorders (Dunkin and Anderson-Hanley, 1998; Hawranik and Strain, 2000).

In the case of the absence of any mental pathology, the dependency for the activities of daily life, the progressive physical deterioration and the amount of activities for which the person is dependent appear strongly related to the caregiver burden (Logdson et al., 1998; Gaugler et al., 2000).

Both the behavioral and functional problems have been linked to the excessive burden of the role, although over time, the behavioral problems are the only ones that are associated with this subjective primary stress factor (Aneshensel et al., 1995; Gaugler et al., 2000). It has been indicated that perhaps the relevancy in the prediction of the caregiver burden is due to the unpredictability and irregularity of the demands. The behavioral problems are not foreseeable nor of regular appearance, as opposed to the characteristics of the disease and the dependency which appear in a more systematic way and are assumed in a more natural way in the caregiver role (Deimling and Bass, 1986; Gaugler et al., 2000).

In relation to the secondary stress factors, the impact of the care situation causes the multiplication or proliferation of emotional discomfort and an excessive burden on other areas of the caregiver's life. The repercussions are diverse and can become evident in the form of a reduction of free time, leisure activities, social relations, appearance of family and matrimonial conflicts (Semple, 1992; Aneshensel et al., 1995).

We also highlight the problems which appear in the employment environment such as: quitting the job, reduction or readjustment of the workday hours, impossibility to access the job market, increases in the workday hours to compensate the loss of income provoked by the care, loss of incomes and negative effects on promotion and job ascent (Havens, 1999; Jenson and Jacobzone, 2000). The possibility of the appearance of these effects increases with a longer period of care, with the greater seriousness of the illness, if the caregiver is a woman as well as an elderly age (Mears, 1998).

The care also has an economic repercussion on the caregiver. In particular, there is a tendency to lose acquisitive power caused by the reduction of the incomes derived from work, as well as those derived by the cost generated by the specific care requirements for the dependent person (Grunfeld et al., 2004). 
On the other hand, the caregiver burden can be alleviated by means of two types of mediators: the strategies of coping and social support. It has been indicated that the strategies focused on the problem (such as problem solving or the redefinition of the care situation) are more effective to alleviate the effects of the caregiver burden and in the reduction of the psychological discomfort than those focused on emotion (Pearlin and Skaff, 1995; Mockus Parks and Novielli, 2000). Nevertheless, it has been defended that this relation is complex and that the different strategies of confrontation have effects based on the phase of the care process in which the caregiver is found, on different emotions, and according to the primary stress factor involved. Specifically, the expertise will only be effective during the in-home care, not during the institutionalization phase, while the strategies of confrontation focused on the problem will be effective to increase the positive effect and those focused on emotion as reducers of the emotional discomfortdepression and anxiety (Aneshensel et al., 1995).

Social support has appeared as another mediator variable of the stress process, either by means of the informal system or the formal resources. Regarding this, the investigation results indicate that the assistance of an instrumental and/or emotional type supplied by family members and neighbors to the informal caregiver is efficient, respectively, to reduce the excessive burden and improve the well-being (Mockus Parks and Novielli, 2000). Nevertheless, these positive effects on the caregiver burden can be eclipsed by the presence of family conflicts (Semple, 1992; Malonebeach and Zarit, 1995).

Similarly, the relief addressed to caregivers provided by the formal resources has been the object of research, especially the respite services and psychosocial intervention programs. The main advantages of these resources is their capacity to reduce the caregiver burden, the tension, and emotional discomfort as well as the negative consequences on the different areas of the caregiver's life, and on the other hand, they make it possible to fulfill the preferences of the dependent person to remain in his/her house and the community in order to receive long-term care, which in fact, is associated with a greater quality of life, well-being, and longevity (Havens, 1999). Consequently, since the formal social support is glimpsed as one of the ideal solutions for the relief of the excessive burden of the informal caregivers of dependent people by means of the application of their services and programs, as the objective of our work, it is described below in a more detailed way.

\section{Intervention programs to alleviate the caregiver burden: the respite services and psychosocial programs}

The respite services essentially refer to the services which are offered to the dependent person and which allow the caregiver to temporarily rest from his/her responsibility and the demands, generated by the continual care. This type of resources includes the In-Home Help Service (HHS), the day care centers, and the residential or overnight cares centers. They permit the substitution of the care provided by the informal caregivers by means of professionals, providing them free time and rest in the performance of their care tasks to the care recipient.

The HHS which includes the provision of care to a dependent person in his/her own residence, and the day care center, which involves care on an outpatient basis during the day of the dependent person in a center where he/she receives the long-term care, comprise the interventions which have shown the greatest efficiency in the reduction of the caregiver's burden, the improvement of the caregiver's physical and mental well-being, as well as a delay in the abandonment of the care process (Zarit, 2002).
Nevertheless, several studies have also appeared which place the effectiveness of this type of programs in doubt; due to the appearance of contradictory results (Mockus Parks and Novielli, 2000). The reasons found in the bibliography concerning these irregular discoveries indicate that this ambiguity could be due to the fact that the respite services: (a) they can have adverse effects if they are not reliable, good quality, and are not adjusted to the requirements of the caregivers and the dependent people (Bass, 2002); (b) they are underused, thus they fail to obtain the expected effects on the caregiver burden (Zarit, 1996); the caregivers demand these resources when they are already exhausted or when the care recipient has a very serious level of dependency. In this case, it has been recommended to use the respite services in a preventive way (Knight et al., 1993; Zarit, 1996); (c) they provide insufficient relief caused by the supply of a very low number of hours and because the caregivers instead of relaxing or dedicating themselves to other leisure activities during the respite service, dedicate the free time that they have to perform other care tasks (Jarrot and Zarit, 1995); and (d) an adequate prior evaluation of the caregiver has not been performed thus it has not been possible to identify the objectives and intervention type most suited to the requirements declared by the caregiver (Gaugler et al., 2000; Friss, 2002).

For their part, the psychosocial intervention programs are destined to improve or increase the caregiver's skills in order to handle the care situations or take care of the patient, where they provide relief to the caregiver's burden and at the same time improve his/her caregiver capacity.

Generally, they include different elements of psychological interventions, ventilation of emotions, mutual help groups, cognitive therapies, counseling, social skills, etc. and educational interventions, supply of information, training in problem solving, etc. Certain evidence has been found in the investigation about the efficiency in the relief of the caregiver burden and the delay in the institutionalization of the dependent person due to this type of programs (Gallagher-Thompson et al., 2003).

In relation to the educational components, their special relevance has been shown in the reduction of the caregiver burden of persons affected by some type of dementia. In this sense, it was possible to verify the influence that the caregiver's behavior has on the impulsive and unpredictable behaviors of the care recipient, in the degree that it is able to decrease or exacerbate these behavioral problems. Thus, it has been affirmed that the interventions on the caregiver's behavior at the time of interacting with the patient can prolong the capacity of the caregiver to continue providing care in the residence and improve the quality of life for both parties. Although it has also been indicated that this type of intervention can generate certain discomfort on the caregiver, consequently the cognitive-behavioral interventions would be the most positive (IPA, 2002).

Certain limitations have also been detected in this type of programs which indicate that: (a) they are addressed to the caregiver in an exclusive way and intervene on him/her in order to reduce his/her burden level, without considering his/her relation to the care recipient; (b) the limited number of intervention sessions hinders the comprehensive training in all the program's contents. In addition, they use general measurements for the burden, which, given the fact that the intervention programs must be brief; they can only achieve changes in isolated dimensions of the stress process; (c) a high number of caregivers refuse to participate in programs focused on reducing their psychological discomfort for two reasons: they think that they do not need help or because they do not have time for it and (d) they have broad effects only if they call for active participation (GallagherThompson et al., 2000; Pinquart and Sörensen, 2006). 


\section{Conclusions}

Several investigations have proposed the suitability of combining both types of programs, the respite services and psychoeducational programs, to deal with the excessive burden of the informal caregivers of dependent people (Carretero et al., 2007; Garcés et al., in press). Specifically in Spain, the use of HHS is an important social resource which exists in the network of Spanish Public Social Services, which would be useful to provide respite to the caregivers of dependent people for their care tasks, at the same time, it allows the dependent person to remain in their home.

Regarding this, some researches have concluded on the relevance to use the following strategies in the design of the social and health care policies to maximize the efficiency of the HHS to relieve the excessive burden (Carretero et al., 2006, 2007; Garcés et al., in press): (a) expanding the type of services provided and the duration of the care provision by the HHS in order to allow the caregiver to rest in a sufficient way and decrease his/her excessive burden levels; (b) increasing the coverage of the needs for the main caregiver, and especially the psychological care requirements by means of the inclusion of psycho-educational programs to alleviate the emotional discomfort of the informal caregivers and provide them with skills and strategies to face the challenge of caregiving. In our context, it is especially important to focus this type of programs to the female population, insofar as recent data indicates that in $84 \%$ of the cases in Spain, the informal care to dependent senior citizens is assumed by a woman (IMSERSO, 2004). As noted by Pinquart and Sörensen (2006), a special care should be given to the quality of these psychoeducational programs, particularly in terms of more structuring and intensity of the interventions; and (c) continuing in the study of other variables of the dependent person and the care context associated to the caregiver burden, in order to analyze the characteristics that can be modifiable in psycho-educational interventions.

\section{Acknowledgments}

The Ministry of Science and Education (SEC 2002, 02634) and the Consellerías de Sanitat y de Bienestar Social of the Generalitat Valenciana (Spain).

\section{References}

AARP, 2006. Fall 2006: Long Term Care. Advancing International Long-Term Care Initiatives through Cross-Atlantic Exchange. Global Report on Aging, AARP. Available at: http://www.aarpinternational.org/gra_sub/gra_sub_show.htm?doc id $=547073$ (Special Issue).

Aneshensel, C., Pearlin, L., Mullan, J., Zarit, S.H., Whitlatch, C.J., 1995. Profiles in Caregiving: The Unexpected Carer. Academic Press, New York.

Bass, D.M., 2002. Content and Implementation of a Caregiver Assessment. Issue Brief. National Family Caregiver Support Program, U.S. Administration on Aging, Washington, DC.

Brodaty, H., Hadzi-Pavlovic, D., 1990. Psychosocial effects on carers of living with persons with dementia. Aust. N Z J. Psychiatry 24, 351-361.

Carretero, S., Garcés, J., Ródenas, F., Sanjosé, V., 2006. La Sobrecarga de las Cuidadoras de Personas Dependientes. Tirant Lo Blanch, Valencia (in Spanish).

Carretero, S., Garcés, J., Ródenas, F., 2007. Evaluation of the home help service and its impact on the informal caregiver's burden of dependent elders. Int. J. Geriatr. Psychiatry 22, 738-749.

Council of Europe, 1998. Recommendation No. R (98) 9 of the Committee of Ministers to Member States on Dependence (Adopted by the Committee of Ministers on 18 September 1998 at the 641st Meeting of the Ministers' Deputies).

Deimling, G., Bass, D., 1986. Symptoms of mental impairment among elderly adults and their effects on family caregivers. J. Gerontol. 41, 778-784.

Dunkin, J.J., Anderson-Hanley, C., 1998. Dementia caregiver burden: a review of the literature and guidelines for assessment and intervention. Neurology 51 (Suppl. 1), S53-S60.

Family Caregiver Alliance (FCA), 2001. Fact Sheet: Selected Caregiver Statistics, Family Caregiver Alliance. Family Caregiver Alliance (FCA), San Francisco.
Friss, L., 2002. The State of the Art: Caregiver Assessment in Practice Settings. Family Caregiver Alliance, San Francisco.

Gallagher-Thompson, D., Lovett, S., Rose, J., McKibbin, C., Coon, D., Futterman, A Thompson, L., 2000. Impact of psychoeducational interventions on distressed family caregivers. J. Clin. Geropsychol. 6, 91-110.

Gallagher-Thompson, D., Coon, D.W., Solano, N., Ambler, C., Rabinowitz, Y., Thompson, L.W., 2003. Change in indices of distress among Latino and Anglo female caregivers of elderly relatives with dementia: site-specific results from the REACH national collaborative study. Gerontologist 43, 580-591.

Garcés, J., Carretero, S., Ródenas, F., Sanjosé, V., in press. Variables related to the informal caregivers' burden of dependent senior citizens in Spain. Arch. Gerontol. Geriatr.

Gaugler, J.E., Kane, R.A., Langlois, J., 2000. Assessment of family caregivers of older adults. In: Kane, R.L., Kane, R.A. (Eds.), Assessing Older Persons: Measures, Meaning and Practical Applications. Oxford University Press, New York, pp. 320-359.

George, L.E., Gwyther, L.P., 1986. Caregiver well-being: A multidimensional examination of family caregivers of demented adults. Gerontologist 26, 253259.

Grad, J., Sainsbury, P., 1963. Mental illness and the family. Lancet i, 544-547.

Grunfeld, E., Coyle, D., Whelan, T., Clinch, J., Reyno, L., Earle, C.C., Willan, A., Viola, R. Coristine, M., Janz, T., Glossop, R., 2004. Family caregiver burden: results of a longitudinal study of breast cancer patients and their principal caregivers. Can. Med. Assoc. J. 170, 1795-1801.

Havens, B., 1999. Home-based and Long-term Care. World Health Organization, Geneva.

Hawranik, P.G., Strain, L.A., 2000. Health of Informal Caregivers: Effects of Gender, Employment, and Use of Home Care Services. Centre on Aging of the University of Manitoba, Manitoba.

IMSERSO, 2004. Situación y evolución del apoyo informal a los mayores en España. Avance de resultados: informe descriptivo, Ministerio de Trabajo y Asuntos Sociales. Secretaría General de Asuntos Sociales, IMSERSO, Madrid (in Spanish).

INE, 2004. Panel de Hogares de la Unión Europea 1994-1999. www.ine.es (in Spanish).

International Psychogeriatric Association (IPA), 2002. Behavioral and Psychological Symptoms of Dementia (BPSD) Educational Pack, Module 4 Role of Care-givers. International Psychogeriatric Association, Illinois.

Jarrot, S.E., Zarit, S.H., 1995. The effects of day care on time usage by employed and non-employed caregivers. In: Proceedings of the 48th Annual Scientific Meeting of the Gerontological Society of America Council, Los Angeles.

Jenson, J., Jacobzone, S., 2000. Care Allowances for the Frail Elderly and their Impact on Women Care-Givers. Labour Market and Social Policy, Occasional Papers no. 41. Directorate for Education, Employment, Labour and Social Affairs; Employment, Labour and Social Affairs Committee (OECD), Paris.

Knight, B.G., Lutzky, S.M., Macofsky-Urban, F., 1993. A meta-analytic review of interventions for caregiver distress: Recommendations for future research. Gerontologist 3, 240-248.

Lazarus, R.S., Folkman, S., 1984. Stress, Appraisal and Coping. Springer, New York.

Lee, S.L., Colditz, G.A., Berkman, L.F., Kawachi, I., 2003. Caregiving and risk of coronary heart disease in U.S. women: a prospective study. Am. J. Prev. Med. 24, 113-119.

Logdson, R.G., Teri, L., McCurry, S.M., Gibbonds, L.E., Kukull, W.A., Larson, E.B. 1998. Wandering: a significant problem among community-residing individuals with Alzheimer's disease. J. Gerontol. B: Psychol. Sci. Soc. Sci. 53, P294P299.

Logdson, R.G., Gibbons, L.E., McCurry, S.M., Teri, L., 1999. Quality of life in Alzheimer's disease: patient and caregiver reports. Gerontologist 5, 21-32.

López, J., López-Arrieta, J., Crespo, M., 2005. Factors associated with the positive impact of caring for elderly and dependent relatives. Arch. Gerontol. Geriatr. 41, 81-94.

Malonebeach, E., Zarit, S., 1995. Dimensions of social support and social conflict as predictors of caregiver depression. Int. Psychogeriatr. 7, 25-36.

Marks, N., Lambert, J.D., Choi, H., 2002. Transitions to caregiving, gender, and psychological well-being: a prospective U.S. national study. J. Marriage Fam. 64, 657-667

Mears, J., 1998. Paying for Care: Repercussions for Women Who Care, the Case of Australia. University of Western Sydney, Department of Social Policy and Human Services, Sydney.

Mockus Parks, S., Novielli, K.D., 2000. A practical guide to caring for caregivers. Am Fam. Physician 15, 2215-2219.

Montgomery, R.J.V., Borgatta, E.F., 1989. The effect of alternative support strategies on family caregivers. Gerontologist 29, 457-464.

Montgomery, R.J.V., Gonyea, J.G., Hooyman, N.R., 1985. Caregiving and the experience of subjective burden. Fam. Relat. 34, 19-26.

Navaie-Waliser, M., Spriggs, A., Feldman, P.H., 2002. Informal caregiving. Differential experiences by gender. Med. Care 40, 1249-1259.

Noonan, A.E., Tennstedt, S.L., 1997. Meaning in caregiving and its contribution to caregiver well-being. Gerontologist 37, 785-794.

Pearlin, L.I., Skaff, M.M., 1995. Stressors in adaptation in late life. In: Gatz, E.M. (Ed.), Emerging Issues in Mental Health and Aging. APA Press, Washington, DC

Pearlin, L.I., Turner, H.A., Semple, S.J., 1989. Coping and the mediation of caregiver stress. In: Light, E., Lebowitz, B. (Eds.), Alzheimer's Disease Treatment and Family Stress: Directions for Research. U.S. Government Printing Office, Washington, DC, pp. 198-217. 
Pearlin, L.I., Mullan, J.T., Semple, S.J., Skaff, M.M., 1990. Caregiving and the stress process: an overview of concepts and their measures. Gerontologist 30, 583-594.

Pinquart, M., Sörensen, S., 2006. Helping caregivers of persons with dementia: which interventions work and how large are their effects? Int. Psychogeriatr. 18, 577-595.

Semple, S.J., 1992. Conflict in Alzheimer's caregiving families: its dimensions and consequences. Gerontologist 32, 648-655.

Yee, J.L., Schulz, R., 2000. Gender differences in psychiatric morbidity among family caregivers: a review and analysis. Gerontologist 2, 147-164.

Zarit, S.H., 1989. Issues and directions in family intervention research. In: Light, E., Lebowitz, B.D. (Eds.), Alzheimer, and Family Stress: Directions for Research. U.S. Government Printing Office, Washington, DC, pp. 458-486.
Zarit, S.H., 1990. Interventions with frail elders and their families: Are they effective and why? In: Parris Stephens, M.A., Crowther, J.H., Hobfoll, S.E., Tennenbaum, D.L. (Eds.), Stress and Coping in Later Life Families. Hemisphere Publishing Company, New York, pp. 241-265.

Zarit, S.H., 1996. Families at the Crossroads: Caring for Disabled Older People. Penn Sate University, Gerontology Center, College of Health and Human Development, Pennsylvania.

Zarit, S.H., 2002. Caregiver's burden. In: Andrieu, S., Aquino, J.P. (Eds.), Family and Professional Carers: Findings Lead to Action. Serdi Edition and Fondation Médéric Alzheimer, Paris, pp. 20-24.

Zarit, S.H., Reever, K.E., Bach-Peterson, J., 1980. Relatives of the impaired elderly: correlates of feelings of burden. Gerontologist 20, 649-654. 